\title{
Association of Panton Valentine Leukocidin $(P V L)$ genes with methicillin resistant Staphylococcus aureus (MRSA) in Western Nepal: a matter of concern for community infections (a hospital based prospective study)
}

Dharm R. Bhatta ${ }^{*}$, Lina M. Cavaco², Gopal Nath³ ${ }^{3}$ Kush Kumar³ ${ }^{3}$ Abhishek Gaur ${ }^{4}$, Shishir Gokhale ${ }^{4}$ and Dwij R. Bhatta'

\begin{abstract}
Background: Methicillin resistant Staphylococcus aureus (MRSA) is a major human pathogen associated with nosocomial and community infections. Panton Valentine leukocidin (PVL) is considered one of the important virulence factors of $S$. aureus responsible for destruction of white blood cells, necrosis and apoptosis and as a marker of community acquired MRSA. This study was aimed to determine the prevalence of PVL genes among MRSA isolates and to check the reliability of PVL as marker of community acquired MRSA isolates from Western Nepal.

Methods: A total of 400 strains of S. aureus were collected from clinical specimens and various units (Operation Theater, Intensive Care Units) of the hospital and 139 of these had been confirmed as MRSA by previous study. Multiplex PCR was used to detect mecA and PVL genes. Clinical data as well as antimicrobial susceptibility data was analyzed and compared among PVL positive and negative MRSA isolates.
\end{abstract}

Results: Out of 139 MRSA isolates, 79 (56.8 \%) were PVL positive. The majority of the community acquired MRSA (90.4 \%) were PVL positive (Positive predictive value: $94.9 \%$ and negative predictive value: $86.6 \%$ ), while PVL was detected only in 4 (7.1\%) hospital associated MRSA strains. None of the MRSA isolates from hospital environment was found positive for the PVL genes. The majority of the PVL positive strains (75.5\%) were isolated from pus samples. Antibiotic resistance among PVL negative MRSA isolates was found higher as compared to PVL positive MRSA.

Conclusion: Our study showed high prevalence of PVL among community acquired MRSA isolates. Absence of $P V L$ among MRSA isolates from hospital environment indicates its poor association with hospital acquired MRSA and therefore, PVL may be used a marker for community acquired MRSA. This is first study from Nepal, to test PVL among MRSA isolates from hospital environment.

Keywords: Staphylococcus aureus, MRSA, PVL, PCR

\footnotetext{
* Correspondence: ddharma2039@gmail.com

${ }^{1}$ Central Department of Microbiology, Tribhuvan University, Kathmandu,

Nepal

Full list of author information is available at the end of the article
} 


\section{Background}

Staphylococcus aureus is one of the most common and important human pathogen associated with broad spectrum of diseases. It is a major cause of hospital acquired infection of surgical wounds and infections associated with indwelling medical devices. Increasing drug resistance among $S$. aureus and the spread of methicillin resistant Staphylococcus aureus (MRSA) are global threat. The resistance of MRSA to $\beta$-lactam antibiotics is associated with penicillin-binding protein $2 \mathrm{a}$, encoded by the mecA gene. The pathogenicity of $S$. aureus is related to a number of virulence factors that allow the organism to adhere, avoid the immune system and cause harmful effects to the host. One of the important cytotoxins produced by some strains of $S$. aureus is the Panton Valentine leukocidin $(P V L)$, encoded by two genes, lukS- $P V$ and lukF-PV [1]. The Panton Valentine leukocidin was named after Sir Philip Noel Panton and Francis Valentine who associated it with soft tissue infections in 1932 [2, 3]. It is a member of the synergohymenotropic toxin family that induces pores in the membranes of cells.

Panton Valentine leukocidin producing MRSA usually cause mild skin or soft tissue infections, however, severe cases of necrotizing pneumonia and sepsis have also been reported [4]. Panton Valentine leukocidin is present in majority of community associated MRSA isolates and rarely present in hospital isolates, therefore it is recognized as marker of community acquired strains [5]. Epidemiological data suggest that high virulence of community acquired MRSA is associated with $P V L$ genes but direct evidence of association of $P V L$ to pathogenesis has been limited [6]. The prevalence of $P V L$ genes among MRSA isolates has not been adequately reported from Nepal. This study was planned to investigate the prevalence of $P V L$ genes among community and hospital- acquired MRSA isolates and to compare drug resistant pattern of $P V L$ positive and $P V L$ negative isolates. Isolates obtained from samples collected from the hospital environment including intensive care units were also included in this study in order to compare the association of PVL with MRSA isolates associated to the hospital environment.

\section{Methods}

This prospective study was conducted at Microbiology laboratory of Manipal Teaching Hospital, Pokhara, Nepal, from September 2012 to August 2013. A total of 400 isolates of $S$. aureus had been collected in previous study [7] and 139 of these isolates had been confirmed as MRSA by susceptibility testing and PCR. These isolates were obtained from clinical specimens of various departments of the hospital (Surgery, Medicine, Intensive Care Units, Post-operative, Burn, Pediatric and Ear
Nose Throat units). Isolates obtained from environmental samples collected from operation theaters and Intensive care units (ICU) were also included.

Isolation and identification of the isolates was performed by standard methods [8]. Antibiotic susceptibility testing was performed by Kirby-Bauer disc diffusion method [9] in previous study and data obtained was used for analysis. Minimal inhibitory concentration (MIC) of vancomycin was performed to rule out the possibility of vancomycin resistant Staphylococcus aureus (VRSA) and vancomycin intermediate Staphylococcus aureus (VISA) following CLSI guidelines [8]. Staphylococcus aureus showing resistance to at least one agent from three or more antimicrobial categories are labelled as multidrug resistant [10].

Hospital and community associated S. aureus isolates were categorized based on the following criteria: Isolates cultured from clinical specimens that were obtained after $72 \mathrm{~h}$ of admission of the patients or from patients with a history of hospitalization within 6 months were considered as hospital-acquired $S$. aureus strains; Isolates which were cultured within $72 \mathrm{~h}$ of hospitalization, from outpatient department (OPD) or patients with no history of hospitalization within 6 months were categorized as community- acquired strains. The clinical information on the patients' clinical background which was used to set the criteria for classification of community and hospital acquired MRSA was obtained from the medical records.

\section{Detection of mecA and PVL genes by multiplex PCR}

DNA was extracted from the MRSA isolates by chloroform: phenol extraction method as described by Sambrook et al. [11]. The primers used for $m e c A$ gene were MecA1 (5'-GTA GAA ATG ACT GAA CGT CCG ATA A) and MecA2 (5'-CCA ATT CCA CAT TGT TTC GGT CTA A) as described earlier by Geha et al. [12]. Primers used for detection of PVL genes were Luk-PV-1 (ATC ATT AGG TAA AAT GTC TGG ACA TGA TCC A) and Luk-PV-2 (GCA TCA AGT GTA TTG GAT AGC AAA AGC) which amplify a 433 base pair fragment specific for $l u k S / F-P V$ genes, encoding the $P V L \mathrm{~S} / \mathrm{F}$ bicomponent proteins as described by McClure et al. [13]. The DNA thermocycler was programmed for initial denaturation at $94{ }^{\circ} \mathrm{C}$ for $4 \mathrm{~min}$; 30 cycles of amplification (denaturation at $94{ }^{\circ} \mathrm{C}$ for $45 \mathrm{~s}$, annealing at $56{ }^{\circ} \mathrm{C}$ for $45 \mathrm{~s}$, and extension at $72{ }^{\circ} \mathrm{C}$ for $30 \mathrm{~s}$ ); and a final extension at $72{ }^{\circ} \mathrm{C}$ for $2 \mathrm{~min}$. To visualize, $10 \mu \mathrm{l}$ of the PCR amplicon was loaded with dye in $1.2 \%$ agarose gel containing ethidium bromide followed by electrophoresis at $100 \mathrm{~V}$ for $1 \mathrm{~h}$ and visualized by using UV transillumination at $310 \mathrm{~nm}$. Fragments of DNA $310 \mathrm{bp}$ corresponded with mecA gene and 433 bp corresponded amplification of a fragment to the $P V L$ genes. 


\section{Data analysis}

Data was analyzed by using Pearson's Chi-square test. A $p$-value of $<0.05$ was considered statistically significant.

\section{Results}

A total of 139 MRSA isolates from various clinical specimens were included in this study. Out of these, $35.2 \%$ (49/139) were HA-MRSA, $59.7 \%$ (83/139) were CAMRSA and $5 \%$ (7/139) were from hospital environment. The genes mecA (310 bp) and PVL (433 bp) were detected by multiplex PCR (Fig. 1). MecA and PVL genes were detected in 79/139 (56.8\%) of the isolates. The majority of the $P V L$ positive isolates were obtained from pus samples accounting for 74/98 (75.5\%). The remaining sample types showed lower percentage of $P V L$ genes whereas among the MRSA from hospital environment samples, none of the isolates were found positive for $P V L$ (Table 1).

The results of antimicrobial susceptibility testing of 139 isolates are shown in Table 2. Our analysis could not find any statistically significant differences in the susceptibility pattern of $P V L$ positive and $P V L$ negative isolates except towards erythromycin. Seventy three percent (102/139) MRSA were multidrug resistant; 50 were $P V L$ positive while 52 were $P V L$ negative. Among the 79 PVL positive isolates, $63.3 \%$ (50/79) were MDR, while this percentage was found significantly higher $86.6 \%$ (52/60) among PVL negative isolates ( $p$ value: $<0.005)$.

Among 37 MRSA isolates which were non MDR, 29 (78.4\%) were $P V L$ positive and $8(21.6 \%)$ were $P V L$ negative. The difference between $P V L$ positive non MDR and $P V L$ positive MDR MRSA was statistically significant ( $p$ value $<0.001)$.

Out of the 139 MRSA isolates, 56 (40.3\%) were found to be hospital associated MRSA and the remaining 83 $(59.7 \%)$ isolates were community associated MRSA by above mentioned clinically based criteria. Among the 83 CA-MRSA, 75 (90.4 \%) were PVL positive while only $7.1 \%(4 / 56)$ HA-MRSA were $P V L$ positive $(p$ value <0.001). All seven MRSA isolates obtained from environmental samples were negative for $P V L$.

\section{Discussion}

Global emergence of MRSA is serious public health problem and challenge to clinicians. A number of factors contribute to the pathogenicity and drug resistance of $S$. aureus. The first PVL positive MRSA was observed in the late 1990 and these strains have become globally distributed in the recent years [14]. The role of PVL in enhancing virulence of $S$. aureus and their pathogenicity is being debated. Panton Valentine leukocidin increases the pathogenicity of $S$. aureus by necrosis, accelerating apoptosis and destruction of polymorphonuclear and mononuclear cells thereby contributing to morbidity and mortality [15]. However, some studies have shown no association of $P V L$ with the virulence of the organism by demonstrating better clinical outcome of skin and soft tissue infections $[16,17]$. Therefore, the role of $P V L$ in clinical outcome is still debated. The reason for the results in clinical outcomes in these studies could be influenced by the effectiveness of antibiotic treatment applied.

Panton Valentine leukocidin is commonly used as a marker for community acquired MRSA, responsible for soft-tissue and deep dermal infections [18, 19]. However, the global scenario of PVL among MRSA isolates varies.

Reports from various countries show the increasing prevalence of $P V L$ among MRSA isolates [20, 21]. Subarna Roy et al. from India, have reported overall $62.85 \%$ of PVL prevalence among MRSA and MSSA (MRSA: $85.1 \%$ and MSSA: $48.8 \%$ ) which indicates a higher prevalence among MRSA than our findings [22]. Similar study by D'Souza et al. from Mumbai, India, reported prevalence of $64 \%$ PVL positive isolates among MRSA [23]. A lower prevalence of $P V L$ has been reported from other parts of world (5 \% in France, $4.9 \%$ in UK, $8.1 \%$ in Saudi Arabia and $14.3 \%$ in Bangladesh) [15, 24-26],

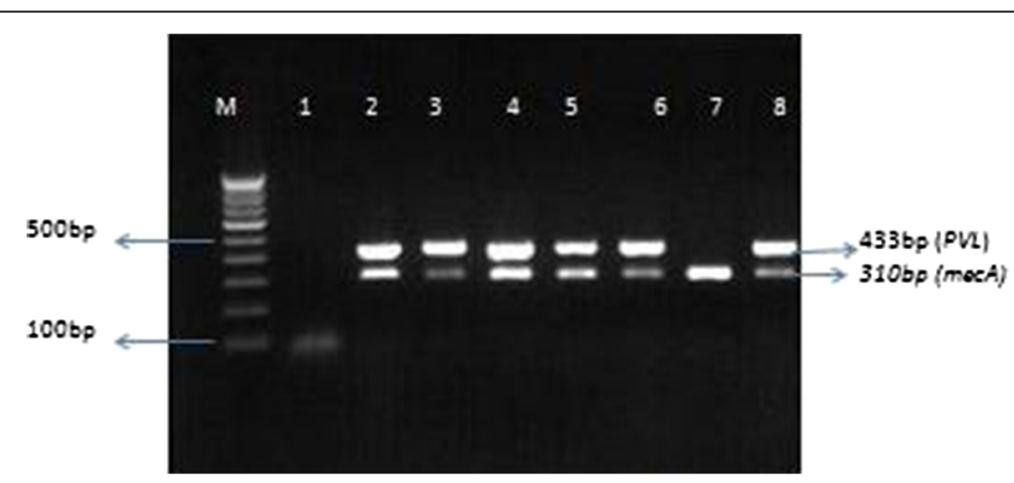

Fig. 1 Multiplex PCR for mecA (310 bp) and PVL (433 bp) genes. M: Marker (100 bp), 1: Negative control, 2: Positive control, 3-8: Test isolates 
Table 1 Distribution of PVL genes among MRSA isolates in different specimens

\begin{tabular}{lll}
\hline Specimen type & Total number of MRSA & PVL positive (\%) \\
\hline Pus & 98 & $74(75.5 \%)$ \\
Blood & 14 & $2(14.3 \%)$ \\
Urine & 12 & $2(16.6 \%)$ \\
Sputum & 6 & $1(16.6 \%)$ \\
Hospital environment & 7 & 0 \\
Body fluids & 2 & 0 \\
\hline
\end{tabular}

reflecting that the prevalence of $P V L$ varies greatly between geographical locations and populations.

This study analyzes the role of $P V L$ in infections at different sites. Skin and soft tissue infections are predominantly $(75.5 \%)$ caused by $P V L$ producing organisms as the leucocidal activity of $P V L$ provides survival advantage to the bacteria. The association of $P V L$ with isolates from other specimens was less. Presence of $P V L$ in deep seated infections like blood stream infections was found less common in our study indicating poor association of $P V L$ with invasiveness of MRSA.

The results of antimicrobial susceptibility testing revealed higher resistance among $P V L$ negative MRSA isolates as compared to $P V L$ positive MRSA isolates, however the differences were not statistically significant except in case of erythromycin (Table 2). Similar finding was observed in case of clindamycin and tetracycline in another study from Nepal [27].

Similarly, the percentage of MDR MRSA among PVL negative $(86.6 \%)$ isolates was found significantly higher than in $P V L$ positive $(63.3 \%)$ isolates ( $p$ value $<0.005)$. These findings suggest that $P V L$ is probably not associated with MDR phenotypes in this study. Similarly, a significantly higher prevalence of $P V L$ was observed among non MDR MRSA.

Association of PVL among male patients was found slightly higher $(54 \%)$ than female (46\%) patients.

Table 2 Antibiotic resistance pattern of PVL positive and PVL negative MRSA isolates

\begin{tabular}{llll}
\hline Antibiotic & $\begin{array}{l}\text { PVL positive MRSA } \\
(n=79) \text { Frequency }(\%)\end{array}$ & $\begin{array}{l}\text { PVL negative MRSA } \\
(n=60) \text { Frequency }(\%)\end{array}$ & $P$ value \\
\hline Penicillin & $79(100 \%)$ & $60(100 \%)$ & - \\
Erythromycin & $52(65.8 \%)$ & $50(83.3 \%)$ & $0.021^{\text {a }}$ \\
Ciprofloxacin & $61(77.2 \%)$ & $51(85 \%)$ & 0.251 \\
Cotrimoxazole & $48(60.7 \%)$ & $45(75 \%)$ & 0.077 \\
Gentamicin & $34(43 \%)$ & $32(53.3 \%)$ & 0.229 \\
Clindamycin & $08(10.1 \%)$ & $07(11.6 \%)$ & 0.772 \\
Amikacin & $06(7.6 \%)$ & $08(13.3 \%)$ & 0.266 \\
Tetracycline & $04(5 \%)$ & $06(10 \%)$ & 0.265 \\
Vancomycin & 00 & 00 & - \\
\hline
\end{tabular}

${ }^{\mathrm{a}}$ Significant association
Higher prevalence of $P V L$ among children $(<14$ years of age) was observed as compared to adults and old age group patients, although difference was statistically insignificant. Similar findings were observed in another study from India [28]. However, some studies have reported strong association of PVL among young children [29]. The highest number (65/79) of PVL-MRSA were isolated from the patients of surgery department, followed by the burn units (5/79), the orthopedic unit (5/79), and other departments (4/79). Similar distribution of $P V L$ positive MRSA isolates in various units of hospital was reported from India [28].

$P V L$ was considered as important marker for differentiation of HA-MRSA and CA-MRSA. In our study, 75 out of 83 CA-MRSA isolates were found PVL positive with positive predictive value $94.9 \%$ and negative predictive value $86.6 \%$. However, some studies have shown association of PVL genes among HA- MRSA isolates also [27, 28]. Most of the studies including our study categorized HA-MRSA and CA-MRSA based upon the history of the patient or by getting information from medical record. However, information obtained from patient or from medical record may not be reliable all the time. To overcome this, we for the first time from Nepal, tested seven isolates of MRSA obtained from the environment of various units of the hospital including wards and intensive care units. As these isolates are not known to be related to the specimen from patients and isolated from hospital environment, we considered them as presumptive hospital strains. These seven isolates were found negative for $P V L$ genes which could indicate that $P V L$ is not normally found in the isolates of hospital environment. However, these isolates are not necessarily representative of hospital environment in general. Absence of $P V L$ in $S$. aureus from inanimate objects of hospital environment may indicate limited role of antileucocytic activity outside the host. In our study, we found association of $P V L$ gene in four MRSA isolates which are hospital acquired as per the clinical criteria described above. As the majority of $P V L$ positive strains represent community isolates, this shows that the criteria set for this study might have limitations and/or these isolates could have been originated from out patients and transmitted to health care workers and patients. To our knowledge, it is likely that these four $P V L$ positive isolates might have been recently transmitted from a community source to hospital settings. In contrast, another study from Nepal reported higher prevalence of $P V L$ among nosocomial MRSA isolates [27].

Limitation of the study: SCCmec typing was not performed in the current study but is planned to be pursued in further studies. 


\section{Conclusion}

The prevalence of the PVL among the MRSA isolates in this study was found relatively high especially among pus samples which indicate a possible key role of $P V L$ in pathogenesis of pyogenic infections especially skin and soft tissue infections in community setting. The $P V L$ positive MRSA isolates showed higher sensitivity against antibiotics as compared to $P V L$ negative isolates indicating that $P V L$ is not associated with drug resistance mechanisms. The presence of $P V L$ among multi drug resistant bacteria like MRSA may be involved in virulence and increase the challenges for clinicians. As expected, the majority of $P V L$ positive MRSA were community-associated isolates, whereas only four MRSA from hospital related cases were found positive for $P V L$. No PVL was detected in MRSA isolated from the hospital environment. In our view, the presence of $P V L$ can be used as a reliable marker for CA-MRSA in these resource limited settings in Nepal.

\section{Ethics approval and consent to participate}

Ethical approval to conduct the study was obtained from the Institutional Ethical Committee (IRC), Manipal College of Medical Sciences (MCOMS), Pokhara, Nepal. Consent of patients was not required as samples were taken as a routine part of care.

\section{Availability of data and materials}

Data supporting the findings can be found in the tables. Data supporting the absence of $P V L$ genes among hospital environmental isolates can be found in the Additional file 1: Figure S1 (Isolate number 20-26 are MRSA isolated from hospital environment showed absence of $P V L$ genes).

\section{Additional file}

Additional file 1: Figure S1. Seven MRSA isolates (Sample number 20-26) from hospital environment showing absence of PVL genes. (DOCX $118 \mathrm{~kb})$

\begin{abstract}
Abbreviations
${ }^{\circ} \mathrm{C}$ : degrees celsius; CA-MRSA: community acquired methicillin resistant Staphylococcus aureus; CLSI: clinical and laboratory standards institute; HA-MRSA: hospital acquired methicillin resistant Staphylococcus aureus; MDR: multidrug resistant; MIC: minimal inhibitory concentration; MRSA: methicillin resistant Staphylococcus aureus; PCR: polymerase chain reaction; PVL: panton valentine leukocidin; VISA: Vancomycin intermediate Staphylococcus aureus; VRSA: Vancomycin resistant Staphylococcus aureus.
\end{abstract}

\section{Competing interests}

The authors declare that they have no competing interests.

\section{Authors' contributions}

DRB worked as principal investigator and contributed in study design, sample collection, processing, data analysis and paper writing. DRB and LMC contributed in formulating objectives, study design and preparing manuscript. GN and KK contributed to molecular studies related to the work at Banaras Hindu University, India. SG and AG contributed to acquisition and analysis of data and refining the manuscript. All authors have read and approved the final manuscript.

\section{Acknowledgement}

We are thankful to all the staff of Microbiology Department, Manipal Teaching Hospital for their support. We would like to thank the Department of Microbiology, Institute of Medical Sciences, Banaras Hindu University $(\mathrm{BHU})$, for their support in conducting molecular work. We are grateful to University Grant Commission (UGC), Nepal, for partial financial support (Ph D Fellowship for faculty category received on 8th April 2013).

\section{Funding}

This study was partially supported by University Grant Commission (UGC), Nepal.

\section{Author details}

${ }^{1}$ Central Department of Microbiology, Tribhuvan University, Kathmandu, Nepal. ${ }^{2}$ Research Group for Genomic Epidemiology, National Food Institute, Technical University of Denmark, Kgs Lyngby, Denmark. ${ }^{3}$ Department of Microbiology, Institute of Medical Sciences, Banaras Hindu University (BHU), Varanasi, India. ${ }^{4}$ Department of Microbiology, Manipal College of Medical Sciences, Pokhara, Nepal.

Received: 5 April 2015 Accepted: 30 April 2016

Published online: 15 May 2016

\section{References}

1. Genestier AL, Michalete MC, Prévoset G, Bellot G, Chalabreysse L, Peyrol S, et al. Staphylococcus aureus Panton-Valentine leukocidin directly targets mitochondria and induces Bax-independent apoptosis of human neutrophils. J Clin Invest. 2005;115:3117-27.

2. Prevost G, Cribier B, Couppie P, Petiau P, Supersac G, Finck-Barbancon V, et al. Panton-Valentine leukocidin and gamma-hemolysin from Staphylococcus aureus ATCC 49775 are encoded by district genetic loci and have different biological activities. Infect Immun. 1995;63:4121-9.

3. Panton P, Valentine F. Staphylococcal toxin. Lancet. 1932;219(5662):506-8.

4. Maltezou HC, Giamarellou H. Community acquired methicillin resistant Staphylococcus aureus infections. Int J Antimicrob Agents. 2006;27:87-96.

5. Vandenesch F, Naimi T, Enright MC, Lina G, Nimmo GR, Heffernan $H$, et al. Community acquired MRSA carrying PVL genes: world-wide emergence. Emer Infect Dis. 2003:9:978-84.

6. Li M, Cheung GYC, Hu J, Wang D, Joo HS, DeLeo FR, et al. Comparative analysis of virulence and toxin expression of global community associated methicillin resistant Staphylococcus aureus strains. J Infect Dis. 2010;12:1866-76

7. Bhatta DR, Cavaco LM, Nath G, Gaur A, Gokhale S, Bhatta DR. Threat of multidrug resistant Staphylococcus aureus in western Nepal. Asian Pac J Trop Dis. 2015;5(8):930-4

8. Cheesbrough M. District laboratory practice in tropical countries. Volume 2. 2nd ed. New York: Cambridge University Press; 2006:62-70.

9. Clinical and Laboratory Standards Institute. Performance standards for antimicrobial susceptibility testing, 21st International Supplements. CLSI Document M100-S21. Wayne: CLSI; 2011.

10. Magiorakos AP, Srinivasan A, Carey RB, Carmeli Y, Falagas ME, Giske G, et al. Multidrug-resistant, extensively drug-resistant and pandrug-resistant bacteria: an international expert proposal for interim standard definitions for acquired resistance. Clin Microbiol Infect. 2012;18:268-81.

11. Sambrook J, Fritsch EF, Maniatis T. Molecular cloning: a laboratory manual, vol 1, 2nd edition. Cold Spring Harbor Laboratory Press. 1989. ISBN 0-87969-309-6, 2344.

12. Geha DJ, Uhl JR, Gustaferro CA, Persing DH. Multiplex PCR for the identification of methicillin-resistant Staphylococci in the clinical laboratory. J Clin Microbiol. 1994;32:1768-72.

13. McClure JA, Conly JM, Lau V, Elsayed S, Louie T, Hutchins W, et al. A novel multiplex PCR assay for the detection of the Staphylococcal virulence marker, the Panton-Valentine Leukocidin genes and the simultaneous discrimination of the methicillin-susceptible from the resistant Staphylococci. J Clin Microbiol. 2006;44(3):1141-4. 
14. Gravet A, Rondeau M, Harf-Monteil C, Grunenberger F, Monteil F, Scheftel JM, et al. Predominant Staphylococcus aureus isolated from antibiotic-associated diarrhea is clinically relevant and produces enterotoxin $\mathrm{A}$ and the bicomponent toxin LukE-LukD. J Clin Microbiol. 1999;37:4012-9

15. Lina G, Piemont Y, Godail-Gamot F, Bes M, Peter MO, Gauduchon V, et al. Involvement of Panton- Valentine leukocidin-producing Staphylococcus aureus in primary skin infections and pneumonia. Clin Infect Dis. 1999;29: 1128-32.

16. Bae IG, Tonthat GT, Stryjewski ME, Rude TH, Reilly LF, Barriere $S L$, et al. Presence of genes encoding the Panton-Valentine leukocidin exotoxin is not the primary determinant of outcome in patients with complicated skin and skin structure infections due to methicillin resistant Staphylococcus aureus: results of a multinational trial. J Clin Microbiol. 2009;47:3952-7.

17. Campbell SJ, Deshmukh HS, Nelson CL, Bae IG, Stryjewski ME, Federspiel JJ, et al. Genotypic characteristics of Staphylococcus aureus isolates from a multinational trial of complicated skin and skin structure infections. J Clin Microbiol. 2008;46:678-84.

18. Havaei SA, Moghadam SO, Pourmand MR, Faghri J. Prevalence of genes encoding bi-component leukocidins among clinical isolates of methicillinresistant Staphylococcus aureus. Iranian J Publ Health. 2010;39:8-14.

19. Miller LG, Perdreau-Remington F, Rieg G, Mehdi H, Perlroth J, Bayer AS, et al. Necrotizing fasciitis caused by community-associated methicillin-resistant Staphylococcus aureus in Los Angeles. N Engl J Med. 2005;352:1445-53.

20. Eckhardt C, Halvosa JS, Ray SM, Blumberg HM. Transmission of methicillinresistant Staphylococcus aureus in the neonatal intensive care unit from a patient with community-acquired disease. Infect Control Hosp Epidemiol. 2003;24:460-1

21. Linde H, Wagenlehner F, Strommenger B, Drubel I, Tanzer J, Reischl U, et al. Healthcare-associated outbreaks and community-acquired infections due to MRSA carrying the Panton-Valentine leukocidin gene in southeastern Germany. Eur J Clin Microbiol Infect Dis. 2005;24:419-22.

22. Kaur H, Purwar S, Saini A, Kaur H, Karadesai SG, Kholkute SD, et al. Status of methicillin resistant Staphylococcus aureus infections and evaluation of PVL producing strains in Belgium. South India JKIMSU. 2012;1:43-51.

23. Souza ND, Rodrigues C, Mehta A. Molecular characterization of methicillin resistant Staphylococcus aureus with emergence of epidemic clones of sequence type (ST) 22 and ST 772 in Mumbai. India J Clin Microbial. 2010; 48:1806-11.

24. Holmes A, Ganner M, McGuane S, Pitt TL, Cookson BD, Kearns AM. Staphylococcus aureus isolates carrying Panton-Valentine leukocidin genes in England and Wales: frequency, characterization, and association with clinical disease. J Clin Microbiol. 2005;43:2384-90.

25. Moussa IM, Shibl AM. Molecular characterization of methicillin-resistant Staphylococcus aureus recovered from outpatient clinics in Riyadh, Saudi Arabia. Saudi Med J. 2008;30:611-7.

26. Afroz S, Kobayashi N, Nagashima S, Alam MM, Hossain ABMB, Rahman MA et al. Genetic characterization of Staphylococcus aureus isolates carrying Panton Valentine Leukocidin genes in Bangladesh. Jpn J Infect Dis. 2008;61: 393-6.

27. Shrestha B, Singh W, Raj VS, Pokhrel BM, Mahapatra TM. High prevalence of Panton-Valentine Leukocidin (PVL) genes in nosocomial-acquired Staphy lococcus aureus isolated from tertiary care hospitals in Nepal. BioMed Research International. 2014;10:1155-61.

28. Bhutia KO, Singh TSK. The prevalence and risk factors which are associated with Staphylococcus aureus and methicillin resistant $\mathrm{S}$. aureus which harboured the Panton Valentine Leukocidin gene in Sikkim. J Clin Diagn Res. 2012;6:393-9.

29. Munckhof WJ, Nimmo GR, Carney J, Schooneveldt JM, Huygens F, Inman-Bamber J, et al. Methicillin susceptible, non-multiresistant methicillin-resistant and multiresistant methicillin-resistant Staphylococcus aureus infections: a clinical, epidemiological and microbiological comparative study. Eur J Clin Microbiol Infect Dis. 2008;27(5):355-64.

\section{Submit your next manuscript to BioMed Central and we will help you at every step:}

- We accept pre-submission inquiries

- Our selector tool helps you to find the most relevant journal

- We provide round the clock customer support

- Convenient online submission

- Thorough peer review

- Inclusion in PubMed and all major indexing services

- Maximum visibility for your research

Submit your manuscript at www.biomedcentral.com/submit
() BioMed Central 